\title{
Palmitoylethanolamide, a Natural Retinoprotectant: Its Putative Relevance for the Treatment of Glaucoma and Diabetic Retinopathy
}

\author{
Jan M. Keppel Hesselink, ${ }^{1,2}$ Ciro Costagliola, ${ }^{3}$ Josiane Fakhry, ${ }^{4}$ and David J. Kopsky ${ }^{2}$ \\ ${ }^{1}$ University of Witten/Herdecke, Alfred-Herrhausen-Straße 50, 58448 Witten, Germany \\ ${ }^{2}$ Institute of Neuropathic Pain, Vespuccistraat 64-III, 1056 SN Amsterdam, Netherlands \\ ${ }^{3}$ Università degli Studi del Molise, Via Francesco De Sanctis, No. 1, 86100 Campobasso, Italy \\ ${ }^{4}$ Faculty of Medicine, Department of Pharmacology and Toxicology, American University of Beirut, P.O. Box 110236, Beirut, Lebanon
}

Correspondence should be addressed to Jan M. Keppel Hesselink; neuropathie7@gmail.com

Received 26 August 2015; Revised 11 October 2015; Accepted 1 November 2015

Academic Editor: Colin Clement

Copyright (C) 2015 Jan M. Keppel Hesselink et al. This is an open access article distributed under the Creative Commons Attribution License, which permits unrestricted use, distribution, and reproduction in any medium, provided the original work is properly cited.

\begin{abstract}
Retinopathy is a threat to the eyesight, and glaucoma and diabetes are the main causes for the damage of retinal cells. Recent insights pointed out a common pathogenetic pathway for both disorders, based on chronic inflammation. Palmitoylethanolamide (PEA) is an endogenous cell protective lipid. Since its discovery in 1957 as a biologically active component in foods and in many living organisms, around 500 scientific papers have been published on PEA's anti-inflammatory and neuron-protective properties. PEA has been evaluated for glaucoma, diabetic retinopathy, and uveitis, pathological states based on chronic inflammation, respiratory disorders, and various pain syndromes in a number of clinical trials since the 70s of 20th century. PEA is available as a food supplement (PeaPure) and as diet food for medical purposes in Italy (Normast, PeaVera, and Visimast). These products are notified in Italy for the nutritional support in glaucoma and neuroinflammation. PEA has been tested in at least 9 double blind placebo controlled studies, among which two studies were in glaucoma, and found to be safe and effective up to $1.8 \mathrm{~g} /$ day, with excellent tolerability. PEA therefore holds a promise in the treatment of a number of retinopathies. We discuss PEA as a putative antiinflammatory and retinoprotectant compound in the treatment of retinopathies, especially related to glaucoma and diabetes.
\end{abstract}

\section{Introduction}

Different types of chronic eye pathologies share a common chronic inflammatory response, which induce in the affected tissues an immunopathological environment responsible for disease progression and a further tissue destruction and abnormal organ homeostasis [1-3]. Among these, it has recently been recognized that age-associated degenerative eye diseases such as glaucoma, age related macular degeneration and diabetic retinopathy, have strong immunological bases; in fact, also for these disorders (neuro)inflammation seems to be a common ground $[1,2,4]$. These new insights prompted us to explore and review the putative role of palmitoylethanolamide (PEA), a peroxisome proliferator-activated receptor alpha (PPAR- $\alpha$ ) ligand that exerts anti-inflammatory, analgesic, and neuroprotective actions [5], for the treatment of (neuro)inflammation, especially related to glaucoma and diabetic retinopathy.

The retina as nervous tissue is highly vulnerable, especially the retinal ganglion cells (RGC), and quickly suffers damage due to a variety of disorders. Protection of the retinal cells against insults and the restoration of damaged tissue are therefore high on the list of ophthalmologists. Neuroprotective and restorative compounds are widely searched for by academia and the pharmaceutical industry. Compounds protecting cells against ischemic and reperfusion damage and immunological, toxic, and metabolic insults might have a therapeutic value for the treatment of retinopathies. There is a high medical need to identify such retinoprotective agents, especially for the treatment of retinopathies due to diabetes 
and glaucoma. Recently it has been recognized that one of the main pathogenetic mechanisms leading to diabetic and glaucomatous retinopathy has its fundament in chronic inflammation, leading amongst others to increased levels of inflammatory cytokines and activation of the NF-kappaB pathway. This was the reason to review the relevance of palmitoylethanolamide for the prevention and treatment of such disorders, as PEA can both inhibit such chronic inflammatory cascades as well as protect neural cells against damage.

Starting in the early 80 s of the 20th century, clinical trials evaluating putative cytoprotective new chemical entities, for instance calcium antagonists, lazaroids, and NMDA antagonists, did not succeed in identifying a therapeutically safe and useful compound [6]. Most compounds, which were cytoprotective in animal models, failed to be effective in humans [7]. In addition, a monotarget approach was proven not to be very useful as most morbid states are defined by a number of pathogenetic pathways. This is the reason why PEA as an endogenous agonist for PPARalpha, which engages multiple transduction systems in the cell to achieve its homeostatic effects, might be so useful. Palmitoylethanolamide (PEA) might be a retinoprotectant, as it has cytoprotective and immune (and glia-) modulating properties and is characterized by multiple tissue-targets (mast cells, glia cells, and retina cells) [8]. PEA lowers intraocular pressure, both in normal and in high-pressure glaucoma, as well as after laser iridotomy [9-12]. In an uveitis model, PEA inhibits inflammation and protects eye tissue [13]. There are also indications for a natural neuroprotective function of PEA in the retinal tissue $[14,15]$. PEA's metabolism has been extensively explored $[5,16]$. It is synthesized from precursors residing in the cell membrane via specific enzymes such as $\mathrm{N}$-acyltransferase and $\mathrm{N}$-acylphosphatidylethanolaminepreferring phospholipase D (NAPE-PLD). The termination of its action is dependent partly on fatty acid amide hydrolase (FAAH) and mostly on $\mathrm{N}$-acylethanolamine-hydrolysing acid amidase (NAAA).

We will review and discuss in this paper the clinical and pharmacological data supporting PEA's use in glaucoma, especially related to the neuroinflammatory factors involved, followed by a discussion of PEA's anti-inflammatory, cytoprotective, and retinaprotective properties. Thereafter, we will present the data related to the inflammatory pathogenesis in diabetic retinopathy and the putative role of PEA in the treatment of such complications.

\section{Palmitoylethanolamide in Glaucoma}

Glaucoma is the second most important cause of blindness in the world, which lead to (i) retinal nerve fiber layer alterations; (ii) optic nerve head cupping; and (iii) typical visual field defect [17]. Elevated intraocular pressure (IOP) has been recognized as the major risk factor for the development of glaucoma and the only modifiable factor associated with the disease [18]. Strong evidence suggests that an early insult occurs to RGC axons at the optic nerve head. The exact mechanisms by which RGC axons are insulted and ultimately degenerate are not clear, although early neuroinflammatory responses seem to suggest a role of inflammation in glaucoma [19].

Lipid messengers and endocannabinoids from the PEA family are synthesized in ocular tissue and have been identified as intraocular pressure reducing compounds. PEA itself however cannot be classified anymore as a pure endocannabinoid; we prefer to define it as a lipid messenger or a lipid autocoid. In animal model anandamide, an example of a pure endocannabinoid ( $50 \mu \mathrm{g}$ to $1 \mathrm{mg}$ ) induced a significant decrease in intraocular pressure (IOP) within 1 hour after topical administration $[20,21]$. The putative role of such protective molecules in the treatment of glaucoma was discussed already a decade ago [22]. With regard to PEA, its concentration is lower in the ciliary body of the eyes of glaucoma patients compared to normal [22]. In states of chronic inflammation, such as diabetic retinopathy and age-related macular degeneration, however, PEA levels were raised, which is explained as an effort of the body to reach homeostasis and downregulate inflammatory pathways [14]. In a model for uveitis exogenous PEA could significantly reduce inflammatory parameters [13]. PEA administration as a depot injection could also significantly increase PEA levels in the retina [23].

In a prospective, randomized, double-blind, crossover clinical trial, 42 patients with raised IOP, treated insufficiently with timolol 0.5\% (IOP remained slightly increased, between 19 and $24 \mathrm{mmHg}$ ), received oral PEA or placebo for 2 months [11]. After a 2-month washout period patients entered the other treatment arm, during 1 month. PEA $(600 \mathrm{mg} /$ day) reduced IOP by $3.2 \pm 1.3 \mathrm{mmHg}$ at 1 month and by $3.5 \pm$ $1.2 \mathrm{mmHg}$ at 2 months. In the placebo group IOP was reduced by $0.4 \pm 1.2 \mathrm{mmHg}$ at 1 month and by $0.3 \pm 1.3 \mathrm{mmHg}$ at 2 months. The difference in IOP reduction was significant for both time points $(p<0.001)$.

In another randomized double-blind placebo-controlled, crossover study, 40 naive ocular hypertensive patients underwent endothelium-dependent flow-mediated dilation measurements (FMD) in addition to the intraocular pressure measurements. Patients were treated by either PEA $(600 \mathrm{mg} /$ day $)$ or a matching placebo for three months. The first treatment period was followed by a two-month washout period. Subsequently patients crossed over to PEA or placebo for another three months. The conclusion was that treatment by PEA during 3 months reduced IOP and led to significantly improved FMD values in ocular hypertensive patients compared to placebo, by ameliorating peripheral endothelial function, and its positive effect lasted longer than the period of PEA consumption, as measured after 2 months of washout. No adverse events were recorded [10].

In another clinical study, intraocular pressure and visual field (VF) damage progression in normal-tension glaucoma (NTG) were evaluated in 32 patients and compared with a control group. Patients were randomized in a 1:1 ratio to receive PEA $(600 \mathrm{mg} /$ day $)$ treatment for 6 months or no treatment for the same period. Best-corrected visual acuity, IOP, and visual field test were evaluated at baseline and at the end of the six-month follow-up. At six months, PEA 
treatment resulted in a significant IOP reduction (from $14.4 \pm$ $3.2 \mathrm{mmHg}$ to $11.1 \pm 4.3 \mathrm{mmHg}, p<0.01$ ). A generalized linear model demonstrated that the final IOP, mean deviation, and pattern standard deviation of the VF were positively affected by the systemic PEA treatment $(p<0.01)$. The conclusion was that PEA reduces IOP and improves visual field indices in individuals affected by NTG. During the study, no side effects were documented [9]. Lastly, in a small controlled pilot trial in 15 patients, PEA lowered the laser iridectomy induced raised IOP compared to placebo, and patients were pretreated with PEA (600 mg/day) or placebo for 2 weeks [12].

In all these studies the effects supported PEA's ocular pressure reducing effects and/or were suggestive for its retinoprotective effects. Although the dose in the studies described above was $600 \mathrm{mg}$ PEA/day, we recommend the double dose $(1200 \mathrm{mg} /$ day) based on practice and due to the fact that various clinical trials dosed at a higher dose ranges, and for PEA there are no dose limiting side effects up to $2400 \mathrm{mg} /$ day. Even doses as high as $2400 \mathrm{mg} /$ day have been used in our clinic in hundreds of patients and are free of such side effects. Furthermore, there are strong pharmacological and clinical indicators for a linear dose effect curve, both in clinical and in preclinical studies, 300-600 mg PEA/day being the low effective dose. Therefore, a higher dose most probably has a greater chance of being effective. A full dose-response study in glaucoma hopefully will be organized in the future.

The mechanism behind PEA's effect on the ocular pressure has been explored using a porcine anterior segmentperfused organ culture model [47]. In that model, PEA caused a concentration-dependent enhancement of outflow facility, with the maximum effect achieved at a low concentration of $30 \mathrm{nM}$ of PEA [47]. PEA also has a number of cell protective properties, and those combined mechanisms could have a significant relevance in the long term treatment of glaucoma. Some of the following findings are supportive for this idea.

Recently, new insights have emerged related to the function of lipid signaling compounds such as PEA in the migration of retinal projections towards their targets [48]. In addition to this a hydrolysis inhibitor, the FAAH inhibitor URB597, of PEA could induce retinal ganglion cell neuroprotection after optic nerve axotomy [49]. Furthermore, PEA and its related molecules could alleviate overactive innate immune responses in Müller glia, and the explorers of that paradigm stated that such therapy may therefore orchestrate a molecular switch to influence the balance of pro- and antiinflammatory cytokine generation in such a way to create, as they called it, "a prosurvival milieu" [50]. The clinical results described above are supported by a vast number of preclinical reports, documenting the anti-inflammatory, neuroprotective properties of PEA and more specifically its retinoprotective properties. In the next two paragraphs some of this evidence will be discussed. The important research question about whether glaucoma affects the metabolism of PEA in the retina is still unanswered. Our hypothesis would be that due to the chronic inflammation either the synthesis of PEA is decreased or its metabolism is increased.

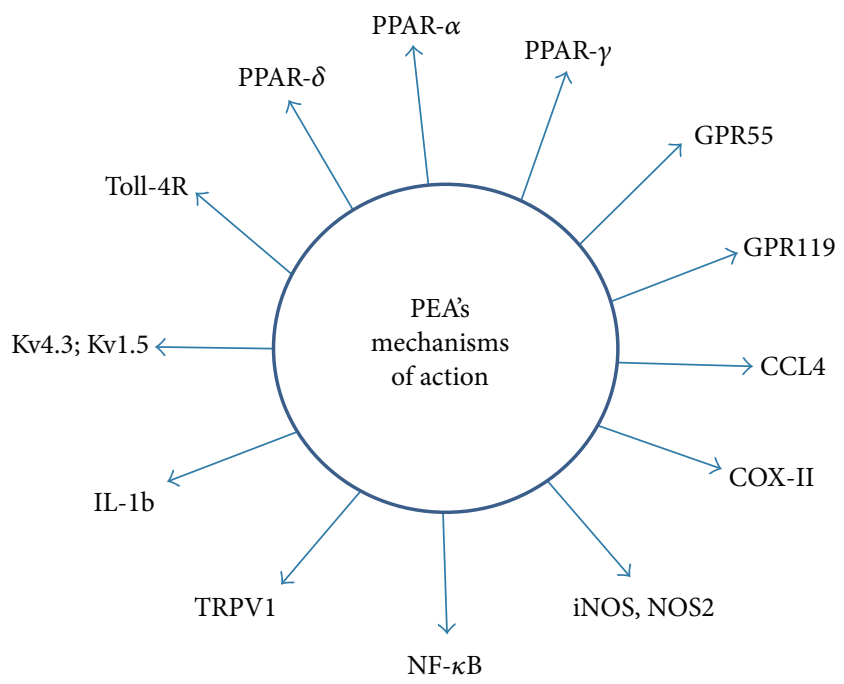

FIGURE 1: Different molecular targets of PEA. PPAR: peroxisome proliferator activated receptor; GPR-55: 119-orphan G-protein coupled receptors; CCL: chemokine ligand; COX: cyclooxygenase; iNOS: inducible nitric oxide synthase; TRPV: transient receptor potential cation channel subfamily V; IL: interleukin; Kv1.5,4.3: potassium voltage gated channels; Toll-4 R: toll-like receptor.

\section{Palmitoylethanolamide: Early Insights in Anti-Inflammatory and Neuroprotective Properties}

PEA is an endogenous evolutionary old molecule that probably came into existence more than 300 million years ago. It can be found in sea urchins and shellfish as well as humans [51]. PEA is a pleiotropic mediator and modulator, having an effect on several receptors (Figure 1) [52]. Its efficacy and tolerability have been documented in over 40 clinical trials in around 5000 patients and its side-effect profile is very benign $[53,54]$. However, due to the fact that PEA is available as a nutraceutical, its therapeutic potential is not well recognized in the medical field yet. PEA however has been proven to be useful in the clinical treatment of chemotherapy induced neuropathy and in a number of nerve compression syndromes supporting PEA's neuroprotective and restorative properties [53-55].

Palmitoylethanolamide is an endogenous signaling lipid in possession of clear anti-inflammatory properties [56]. Its value as a prophylactic and therapeutic agent for flu and common cold was evaluated in the 70s of the 20th century [57-59]. During this period, it also became clear that PEA was synthesized in many different tissues. Decades ago, it is understood that PEA and related $\mathrm{N}$-acetylethanolamines protect cells against insults, such as ischemia, immunological pathologies, and damage. For instance, PEA accumulates in infarcted tissue, while it could not be detected in the healthy heart and brain tissues [60]. PEA and related lipids were also documented to exist in different vertebrates, even in invertebrates, as well as in a great number of organs, including the brain and the spinal cord [61, 62]. In 1993, the Nobel laureate Rita Levi-Montalcini shed new light on how PEA could 
achieve its specific properties in her milestone paper [63]. In that paper, she described a number of experiments where orally administered PEA to rats could inhibit overactive mast cells (MCs) and reduce local inflammatory markers such as tumor necrosis factor- $\alpha$ (TNF- $\alpha$ ). Few years later, she was the first to discuss PEA's organ specific, neuroprotective properties, and PEA's mechanism of action [64]. Levi-Montalcini and coworkers were also first to propose the ALIA mechanism or the "Autacoid Local Inflammation Antagonism," later modified into "Autacoid Local Injury Antagonism" and defined PEA as such an "ALIAmide." An ALIAmide is an autacoid synthesized and released in response to injury or inflammation acting locally to counteract the pathological events $[65,66]$. However, in some chronic inflammatory states, PEA tissue levels can also be decreased, either due to decreased synthesis or due to enhanced metabolism [66]. Compounds such as PEA thus can be seen as endogenous protective and reparative molecules. Her work however did not lead to the identification of the main molecular target of PEA. Only many years later the link between these properties and the effect of PEA on the nuclear receptor PPAR- $\alpha$ was understood, based on the seminal work of Piomelli and LoVerme and colleagues $[67,68]$.

\section{Palmitoylethanolamide: Retina-Protective Properties}

As the retina consists of nervous tissue, neuroprotective properties of molecules can also be regarded as an indication for retinoprotective activity. N-Acetylethanolamines (NAEs) are lipophilic, autocrine signaling molecules formed in all tissues on demand from membrane phospholipids called Nacylated-phosphatidylethanolamines. The notable examples include PEA, oleoylethanolamide, stearoylethanolamide, and anandamide (arachidonoyl-ethanolamide (AEA)). PEA, a structural relative of anandamide, is a saturated NAE (C16:0) with a palmitoyl moiety. PEA and AEA are also present in peripheral tissues as well as in the central nervous system, with the former being ten times more abundant [69]. Specific noxious stimuli may lead to their independent accumulation. For instance, in an animal model of autoimmune encephalomyelitis, there was a clear increase in PEA levels [70].

Many of the known biological properties of PEA pointing to its putative retina-protective properties can be explained through the dose dependent modulation of peroxisome proliferator-activated receptors, especially the PPAR- $\alpha$ receptor. The numbers of PEA targets are currently increasing. Recently it was described that PEA inhibits the induction of the proinflammatory genes IL-1b, CCL4, and NOS2 and adhesion molecules such as ICAM-1 and P-selectin [71]. CCL4 can induce monocyte migration and this migration is also blocked by PEA [72]. The receptor system however that mediates the majority of the agent's effects in the case of PEA is due to activation of PPAR- $\alpha$ and downstream secondary targets such as NF- $\kappa \mathrm{B}$, TNF-alpha, Illb, and ICAM, as listed in Figure 1. Evidence for roles of GPR55 and GPR119 however remains scant. Figure 1 shows a number of known targets of PEA.

Both PPAR- $\alpha$ and PEA are present in nervous tissue and their expression may show large changes during pathological conditions. Currently there seems to be a consensus in the literature regarding the idea that the PPAR family is one of the primary targets of PEA. Through activation of the PPARs, especially PPAR- $\alpha$, PEA is attenuating proinflammatory mediators and/or increasing anti-inflammatory mediators $[42,73]$. However, the role of PEA is not thought to be limited to the action on PPAR- $\alpha$, as different targets such as PPAR- $\delta$ and PPAR- $\gamma$ clearly play an additional role. In fact, a study conducted on spinal cord injured mice showed that PEA treatment induced a limited infiltration of inflammatory cells, a protective effect that was attenuated after treatment with PPAR- $\gamma$ and PPAR- $\delta$ antagonists. PEA increases PPAR- $\alpha$ and PPAR- $\gamma$ expression, thus restoring any neuroinflammation induced downregulation of these receptors [39]. Activation of PPAR- $\delta$ inhibited streptozotocin-induced diabetic nephropathy through anti-inflammatory mechanisms [74]. PEA was also seen to show anti-inflammatory effects in nonneuronal tissues. For instance, it downmodulates skin MC activation and hence reduces immunologically induced release of histamine, $\mathrm{PGD}_{2}$, and TNF $\alpha$ [75]. PEA reduces spinal cord inflammation and tissue injury with significant reduction of nitrotyrosine formation, proinflammatory cytokine expression, NF- $\kappa \mathrm{B}$ activation, inducible nitric-oxide synthase expression, and apoptosis [46]. Colon inflammation was also seen to be improved by PEA, and proinflammatory markers and macroscopic signs of ulcerative colitis were decreased [33]. Downstream inhibition of NF- $\kappa$ B by PPAR- $\alpha$ was responsible for the effects, as the effects were abolished by a specific antagonist. PEA is also able to upregulate the various PPAR receptors in damaged tissue [76]. These upregulated and activated receptors are key for many downstream effects of PEA. PEA at a dose of $10 \mathrm{mg} / \mathrm{kg}$ intraperitoneally protected nigrostriatal neurons from neurotoxicity and neuroinflammation [43]. PEA remains neuroprotective even when administered once the insult has been initiated. PEA had shown superior neuroprotective activity compared to minocycline (TNF- $\alpha$ agonist) in models of neurotoxicity [43]. In mice models of Alzheimer's disease, PEA reduced the increased lipid peroxidation, protein nitration, inducible nitric oxide synthase expression, and the induction of proapoptotic pathways induced by amyloid injection [77]. PEA counteracted the negative effects of amyloid on cell viability in cultured cortical neurons and astrocytes [26]. Despite the fact that PPAR- $\alpha$ is the most probable target for these effects, PPAR- $\gamma$ and PPAR- $\delta$ were shown also to contribute to the neuroprotective role. PPAR- $\gamma$ and PPAR- $\delta$ presence is reported in spinal cord under physiological conditions. In one study, 24 hours after spinal cord injury, PPAR- $\gamma$ and PPAR- $\delta$ expression was significantly reduced in spinal cord homogenates. PEA treatment could significantly restore these decreases again to normal basal levels. Therefore, the antiinflammatory and protective effects of PEA are favored by the presence of PPAR- $\alpha$, PPAR- $\delta$, and PPAR- $\gamma$ receptors at various sites [39]. 
TABLE 1: Summary of preclinical studies related to PEA's cytoprotective effects.

\begin{tabular}{|c|c|c|c|}
\hline Year & Dose PEA & Main results & Reference \\
\hline 2015 & $5 \mu \mathrm{M}$ in vitro & Inhibition of the $\mathrm{Ca}^{2+}$-dependent release of glutamate & {$[24]$} \\
\hline 2015 & $5 \mathrm{mg} / \mathrm{kg}$ & $\begin{array}{l}\text { Diminished inflammation, demyelination, axonal damage, and inflammatory cytokine expression } \\
\text { in a multiple sclerosis model }\end{array}$ & [25] \\
\hline 2015 & $0.1 \mu \mathrm{M}$ in vitro & Protection cell viability in cultured cortical neurons and astrocytes against inflammation & [26] \\
\hline 2015 & $10^{-8}-10^{-6} \mathrm{M}$ & Concentration-dependently reduced expression of proinflammatory and proangiogenic markers & [27] \\
\hline 2014 & $1 \mathrm{mg} / \mathrm{kg}$ & Prevention of induced afferent mechanical sensitization & {$[28]$} \\
\hline 2014 & $\begin{array}{l}200,400 \text { and } \\
800 \mu \mathrm{g} / \mathrm{mL}\end{array}$ & Inhibition of inflammation markers and chymase expression in granulomatous tissue & [29] \\
\hline 2014 & $30 \mathrm{mg} / \mathrm{kg} \mathrm{sc}$ & $\begin{array}{l}\text { Increased AMP-activated protein kinase- } \alpha \text { phosphorylation and carnitine palmitoyltransferase } 1 \\
\text { transcription in adipose tissue; polarized adipose tissue macrophages to M2 lean phenotype }\end{array}$ & {$[30]$} \\
\hline 2014 & $10 \mathrm{mg} / \mathrm{kg}$ & $\begin{array}{l}\text { Reduction of structural radiation injury, intestinal wall thickness, collagen deposition, intestinal } \\
\text { inflammation, and increased anti-inflammatory IL-10 and IL-6 }\end{array}$ & [31] \\
\hline 2013 & $10 \mathrm{mg} / \mathrm{kg}$ & $\begin{array}{l}\text { Reduction of the clinical signs of type II collagen-induced arthritis as well as of paw edema } \\
\text { compared to control }\end{array}$ & [32] \\
\hline 2013 & $\begin{array}{l}2,10 \mathrm{or} \\
50 \mathrm{mg} / \mathrm{kg}\end{array}$ & $\begin{array}{l}\text { Improves all macroscopic signs of colitis and decreases the expression and release of all the } \\
\text { proinflammatory markers }\end{array}$ & [33] \\
\hline 2013 & $30 \mathrm{mg} / \mathrm{kg}$ & Reduction of hypertension and protects kidney injury & [34] \\
\hline 2013 & $\begin{array}{l}1 \mu \mathrm{M} \text { control in } \\
\text { vivo }\end{array}$ & Protected SCI-associated neuroinflammation in vivo and in vitro & {$[35]$} \\
\hline 2013 & $0.1 \mu \mathrm{M}$, in vitro & $\begin{array}{l}\text { Rescue of neuron damage by amyloid and reduction of neuroinflammation (decrease of astrocyte } \\
\text { activation) }\end{array}$ & {$[36]$} \\
\hline 2013 & $5-10 \mathrm{mg} / \mathrm{kg}$ & $\begin{array}{l}\text { Normalizing the activity of sensitized nociceptive neurons; significant reduction of mechanical } \\
\text { allodynia and thermal hyperalgesia in a dose-dependent manner }\end{array}$ & {$[37]$} \\
\hline 2013 & $10 \mathrm{mg} / \mathrm{kg}$ & $\begin{array}{l}\text { Strong reduction of microglia activation and PEA delayed mast cell recruitment, protection of } \\
\text { mast cells against degranulation, and abolition of the nerve growth factor increase, reducing pain }\end{array}$ & {$[38]$} \\
\hline 2013 & $10 \mathrm{mg} / \mathrm{kg}$ & $\begin{array}{l}\text { Protection of spinal cord damage; restoration of PPAR- } \delta \text { and PPAR- } \gamma \text { expression in spinal cord } \\
\text { after damage }\end{array}$ & [39] \\
\hline 2013 & $\begin{array}{l}10,20,40 \\
60 \mathrm{mg} / \mathrm{kg} \text { i.p. }\end{array}$ & Showing anti-epileptic properties in a rat model & {$[40]$} \\
\hline 2013 & NR & Blunted $A \beta 1-42$-induced neurotoxicity and controlled glial activation & [41] \\
\hline 2012 & $10 \mathrm{mg} / \mathrm{kg}$ & $\begin{array}{l}\text { Significant attenuation of the degree of renal dysfunction, injury, and inflammation caused by } \\
\text { ischemia-reperfusion injury }\end{array}$ & {$[42]$} \\
\hline 2012 & $10 \mathrm{mg} / \mathrm{kg}$ & $\begin{array}{l}\text { Reduction of MPTP-induced microglial activation, the number of GFAP-positive astrocytes, and } \\
\text { reduction of neutrophil infiltrations, reduction of TNF- } \alpha \text {, IL- } 1 \beta \text { and iNOS in spinal cord and } \\
\text { prevention of SCI-induced I } \kappa \text { B- } \alpha \text { degradation and Bax expression }\end{array}$ & [43] \\
\hline 2012 & $10 \mathrm{mg} / \mathrm{kg}$ & Reduction of apoptosis, brain infarctions, and various inflammatory parameters & [44] \\
\hline 2011 & $10 \mathrm{mg} / \mathrm{kg}$ & $\begin{array}{l}\text { Significant reduction of mast cell infiltration, expression of mediators like NGF, the activation of } \\
\text { microglia, and astrocytes expressing cannabinoid } \mathrm{CB}(2) \text { receptor after spinal cord injury }\end{array}$ & {$[45]$} \\
\hline 2008 & $10 \mathrm{mg} / \mathrm{kg}$ & $\begin{array}{l}\text { Significant reduction of spinal cord inflammation and tissue injury, neutrophil infiltration, and } \\
\text { proinflammatory cytokine expression and significant amelioration of the recovery of motor limb } \\
\text { function }\end{array}$ & {$[46]$} \\
\hline
\end{tabular}

NR: Nonreported.

The putative retinoprotective properties of PEA are based on the same mechanisms as the neuroprotective and cytoprotective properties. In Table 1 an overview is given of studies supporting PEA's cytoprotective properties.

\section{PEA and Its Putative Relevance for the Treatment of Diabetic Retinopathy}

Diabetic retinopathy is the most common microvascular complication of diabetes mellitus and the main cause of blindness within the working-age population in industrialized nations [78]. More recently new pathways which may be involved in the pathogenesis of diabetic retinopathy have been identified, such as inflammation, nerve growth factor autophagy, and epigenetics. Epidemiologic studies have shown an association between the appearance of inflammatory biomarkers and the occurrence of type 2 diabetes mellitus and its complications [79]. Diabetics have increased levels of inflammatory markers, including C-reactive protein (CRP), interleukin-6 (IL-6), and TNF- $\alpha$ [80]. There 
is increasing evidence that inflammatory processes play a considerable role in the pathogenesis of DR [81].

PEA most probably produces retinoprotection via its anti-inflammatory properties we described above, preventing oxidant stress and inhibition overactivation of Müller cells mircoglia and asterocytes. This activation of the innate immune response in the retina is thought to be triggered by advanced glycation end products (AGE) [82]. The retinal Müller cells are the major source of inflammatory cytokines in the retina [83]. But microglia and asterocytes also play a role [84]. The hyperglycemia leads in many cases to an increased production of proinflammatory cytokines by the Müller cells and asterocytes, such as IL-1 $\beta$ [85]. PEA has been found in the past to inhibit overactivation of various glia cells. In a rat astrocyte model, PEA downregulates reactive gliosis by reducing proinflammatory molecules and cytokine release through the inhibition of NF- $\kappa$ B. PEA causes a marked reduction of astrocyte activation and provides neuronal protection in both mixed neuroglial and organotypic hippocampal cultures [27]. These findings are relevant, as retina glia cell activation is also thought to be an important pathogenetic element not only in diabetic retinopathy but also in glaucoma $[28,86]$.

Toll-like receptors (TLRs) play also an important role in innate immune responses and inflammation and the pathogenesis of diabetic retinopathy [87]. TLR-4 for instance is upregulated in hyperglycemia and TLR-4 activation and this activation leads to increased inflammation possibly via reactive oxygen species (ROS) and the authors suggested this pathway also could contribute to DR. In different paradigms, the same pathogenetic role for TLR-4 in DR has been postulated [88]. TLR-4 polymorphisms are also suggested to increase the risk for DR in Diabetes type 2 patients [89]. PEA inhibits TLR- 4 activity and downregulates TLR- 4 triggered inflammation cascades [33].

PEA thus has the potential to inhibit these various proinflammatory activated cascades, which seems relevant to the treatment of both diabetic retinopathy and glaucoma.

\section{Conclusion}

PEA's safety and efficacy have been evaluated in a number of clinical trials in inflammatory conditions and chronic pain states, including glaucoma. PEA has been shown to be safe and effective up to $1.8 \mathrm{gm} /$ day [58], due to its mechanisms of action and remarkable safety, without any documented drug-drug interaction. Due to the convergent pathogenetic pathways related to retinal glia activation, PEA holds a promise for both glaucoma as well as diabetic retinopathy.

PEA is a pleiotropic naturally occurring endogenous $\mathrm{N}$ acetylethanolamine that plays an important biological role in many living organisms, including humans. Its beneficial effects are dose dependent and mediated through various receptors such as PPAR- $\alpha$, PPAR- $\gamma$, PPAR- $\delta$, GPR 119, and TRPV1. PEA is known to downregulate proinflammatory genes and possess a broad anti-inflammatory, antioxidant, and cytoprotective activities. As both glaucoma and diabetic retinopathy share a common pathogenetic pathway, PEA should be considered in the treatment and prophylaxis of retinal damage in both disorders.

\section{List of Abbreviations}

AEA: Arachidonoyl-ethanolamide

DR: Diabetic retinopathy

IOP: Intraocular pressure

MC: $\quad$ Mast cell

NAE: N-Acetylethanolamine

PEA: Palmitoylethanolamide

PPAR: Peroxisome proliferator activated receptor

ROS: Reactive oxygen species

TNF- $\alpha$ : Tumor necrosis factor- $\alpha$.

\section{Disclosure}

All authors approved the final version submitted.

\section{Conflict of Interests}

The authors declare that they have no conflict of interests to disclose.

\section{Authors' Contribution}

Dr. Josiane Fakhry contributed to the chapters related to PEA's anti-inflammatory mechanism of action and its effects on the PPAR receptors. Professor Ciro Costagliola reviewed the entire paper and contributed significantly to the chapters related to glaucoma and diabetic retinopathy. Dr. David J. Kopsky helped editing of the paper and provided input on the pharmacology of PEA. Professor Jan M. Keppel Hesselink drafted and edited the major part of the paper.

\section{Acknowledgment}

The authors want to express their thanks to Dr. Ashenafi Haileyesus Betrie, who contributed significantly to the pharmacological part of the paper.

\section{References}

[1] D. Križaj, D. A. Ryskamp, N. Tian et al., "From mechanosensitivity to inflammatory responses: new players in the pathology of glaucoma," Current Eye Research, vol. 39, no. 2, pp. 105-119, 2014.

[2] V. L. Perez and R. R. Caspi, "Immune mechanisms in inflammatory and degenerative eye disease," Trends in Immunology, vol. 36, no. 6, pp. 354-363, 2015.

[3] C. E. Gallenga, F. Parmeggiani, C. Costagliola, A. Sebastiani, and P. E. Gallenga, "Inflammaging: should this term be suitable for age related macular degeneration too?" Inflammation Research, vol. 63, no. 2, pp. 105-107, 2014.

[4] F. Semeraro, A. Cancarini, R. dell'Omo, S. Rezzola, M. R. Romano, and C. Costagliola, "Diabetic retinopathy: vascular and inflammatory disease," Journal of Diabetes Research, vol. 2015, Article ID 582060, 16 pages, 2015. 
[5] M. Alhouayek and G. G. Muccioli, "Harnessing the antiinflammatory potential of palmitoylethanolamide," Drug Discovery Today, vol. 19, no. 10, pp. 1632-1639, 2014.

[6] A. Schmidt, J. Minnerup, and C. Kleinschnitz, "Emerging neuroprotective drugs for the treatment of acute ischaemic stroke," Expert Opinion on Emerging Drugs, vol. 18, no. 2, pp. 109-120, 2013.

[7] P. Mergenthaler and A. Meisel, "Do stroke models model stroke?" Disease Models and Mechanisms, vol. 5, no. 6, pp. 718$725,2012$.

[8] J. M. Keppel Hesselink, D. J. Kopsky, and R. F. Witkamp, “Palmitoylethanolamide (PEA)-'promiscuous' anti-inflammatory and analgesic molecule at the interface between nutrition and pharma," PharmaNutrition, vol. 2, no. 1, pp. 19-25, 2014.

[9] C. Costagliola, M. R. Romano, R. Dell'Omo, A. Russo, R. Mastropasqua, and F. Semeraro, "Effect of palmitoylethanolamide on visual field damage progression in normal tension glaucoma patients: results of an open-label six-month follow-up," Journal of Medicinal Food, vol. 17, no. 9, pp. 949-954, 2014.

[10] E. Strobbe, M. Cellini, and E. C. Campos, "Effectiveness of palmitoylethanolamide on endothelial dysfunction in ocular hypertensive patients: a randomized, placebo-controlled crossover study," Investigative Ophthalmology \& Visual Science, vol. 54, no. 2, pp. 968-973, 2013.

[11] C. Gagliano, E. Ortisi, L. Pulvirenti et al., "Ocular hypotensive effect of oral palmitoyl-ethanolamide: a clinical trial," Investigative Ophthalmology and Visual Science, vol. 52, no. 9, pp. 60966100, 2011.

[12] N. Pescosolido, A. Librando, M. Puzzono, and M. Nebbioso, "Palmitoylethanolamide effects on intraocular pressure after Nd: YAG laser iridotomy: an experimental clinical study," Journal of Ocular Pharmacology and Therapeutics, vol. 27, no. 6, pp. 629-635, 2011.

[13] D. Impellizzeri, A. Ahmad, G. Bruschetta et al., "The antiinflammatory effects of palmitoylethanolamide (PEA) on endotoxin-induced uveitis in rats," European Journal of Pharmacology, vol. 761, pp. 28-35, 2015.

[14] I. Matias, J. W. Wang, A. S. Moriello, A. Nieves, D. F. Woodward, and V. Di Marzo, "Changes in endocannabinoid and palmitoylethanolamide levels in eye tissues of patients with diabetic retinopathy and age-related macular degeneration," Prostaglandins Leukotrienes and Essential Fatty Acids, vol. 75, no. 6, pp. 413-418, 2006.

[15] N. Pescosolido and M. Puzzono, "First clinical case of effective medical treatment of the vitreoretinal traction with recovery of the visual acuity," La Clinica Terapeutica, vol. 161, no. 4, pp. e143e147, 2010.

[16] I. A. S. Rahman, K. Tsuboi, T. Uyama, and N. Ueda, "New players in the fatty acyl ethanolamide metabolism," Pharmacological Research, vol. 86, pp. 1-10, 2014.

[17] C. Costagliola, R. Dell'Omo, M. R. Romano, M. Rinaldi, L. Zeppa, and F. Parmeggiani, "Pharmacotherapy of intraocular pressure: part I. Parasympathomimetic, sympathomimetic," Expert Opinion on Pharmacotherapy, vol. 10, no. 16, pp. 26632677, 2009.

[18] A. L. Coleman and S. Miglior, "Risk factors for glaucoma onset and progression," Survey of Ophthalmology, vol. 53, supplement, no. 6, pp. S3-S10, 2008.

[19] I. Soto and G. R. Howell, "The complex role of neuroinflammation in glaucoma," Cold Spring Harbor Perspectives in Medicine, vol. 4, no. 8, Article ID a017269, 2014.
[20] S. Matsuda, N. Kanemitsu, A. Nakamura et al., "Metabolism of anandamide, an endogenous cannabinoid receptor ligand, in porcine ocular tissues," Experimental Eye Research, vol. 64, no. 5, pp. 707-711, 1997.

[21] Y. Mikawa, S. Matsuda, T. Kanagawa, T. Tajika, N. Ueda, and Y. Mimura, "Ocular activity of topically administered anandamide in the rabbit," Japanese Journal of Ophthalmology, vol. 41, no. 4, pp. 217-220, 1997.

[22] J. Chen, I. Matias, T. Dinh et al., "Finding of endocannabinoids in human eye tissues: implications for glaucoma," Biochemical and Biophysical Research Communications, vol. 330, no. 4, pp. 1062-1067, 2005.

[23] S. L. Grillo, J. Keereetaweep, M. A. Grillo, K. D. Chapman, and P. Koulen, "N-palmitoylethanolamine depot injection increased its tissue levels and those of other acylethanolamide lipids," Drug Design, Development and Therapy, vol. 7, pp. 747-752, 2013.

[24] T. Y. Lin, C. W. Lu, C. C. Wu, S. K. Huang, and S. J. Wang, "Palmitoylethanolamide inhibits glutamate release in rat cerebrocortical nerve terminals," International Journal of Molecular Sciences, vol. 16, no. 3, pp. 5555-5571, 2015.

[25] A. Rahimi, M. Faizi, F. Talebi, F. Noorbakhsh, F. Kahrizi, and N. Naderi, "Interaction between the protective effects of cannabidiol and palmitoylethanolamide in experimental model of multiple sclerosis in C57BL/6 mice," Neuroscience, vol. 290, pp. 279-287, 2015.

[26] M. C. Tomasini, A. C. Borelli, S. Beggiato et al., "Differential effects of palmitoylethanolamide against amyloid-beta induced toxicity in cortical neuronal and astrocytic primary cultures from wild-type and 3xTg-AD mice," Journal of Alzheimer's Disease, In press.

[27] M. Cipriano, G. Esposito, L. Negro et al., "Palmitoylethanolamide regulates production of pro-angiogenic mediators in a model of $\beta$ amyloid-induced astrogliosis in vitro," CNS \& Neurological Disorders_Drug Targets, vol. 14, no. 7, pp. 828-837, 2015.

[28] B. E. Cairns, J. C. Laursen, X.-D. Dong, and P. Gazerani, "Intraganglionic injection of a nitric oxide donator induces afferent mechanical sensitization that is attenuated by palmitoylethanolamide," Cephalalgia, vol. 34, no. 9, pp. 686-694, 2014.

[29] D. De Filippis, A. Russo, D. De Stefano et al., "Palmitoylethanolamide inhibits rMCP-5 expression by regulating MITF activation in rat chronic granulomatous inflammation," European Journal of Pharmacology, vol. 725, no. 1, pp. 64-69, 2014.

[30] G. M. Raso, A. Santoro, R. Russo et al., "Palmitoylethanolamide prevents metabolic alterations and restores leptin sensitivity in ovariectomized rats," Endocrinology, vol. 155, no. 4, pp. 12911301, 2014.

[31] J. Wang, J. Zheng, A. Kulkarni et al., "Palmitoylethanolamide regulates development of intestinal radiation injury in a mast cell-dependent manner," Digestive Diseases and Sciences, vol. 59, no. 11, pp. 2693-2703, 2014.

[32] D. Impellizzeri, E. Esposito, R. Di Paola et al., "Palmitoylethanolamide and luteolin ameliorate development of arthritis caused by injection of collagen type II in mice," Arthritis Research \& Therapy, vol. 15, no. 6, article R192, 2013.

[33] G. Esposito, E. Capoccia, F. Turco et al., "Palmitoylethanolamide improves colon inflammation through an enteric glia/toll like receptor 4-dependent PPAR- $\alpha$ activation," Gut, vol. 63, no. 8, pp. 1300-1312, 2014. 
[34] G. M. Raso, R. Simeoli, R. Russo et al., "N-Palmitoylethanolamide protects the kidney from hypertensive injury in spontaneously hypertensive rats via inhibition of oxidative stress," Pharmacological Research, vol. 76, pp. 67-76, 2013.

[35] I. Paterniti, D. Impellizzeri, R. Di Paola, M. Navarra, S. Cuzzocrea, and E. Esposito, "A new co-ultramicronized composite including palmitoylethanolamide and luteolin to prevent neuroinflammation in spinal cord injury," Journal of Neuroinflammation, vol. 10, article 91, 2013.

[36] C. Scuderi and L. Steardo, "Neuroglial roots of neurodegenerative diseases: therapeutic potential of palmitoylethanolamide in models of alzheimer's disease," CNS \& Neurological DisordersDrug Targets, vol. 12, no. 1, pp. 62-69, 2013.

[37] L. Luongo, F. Guida, S. Boccella et al., "Palmitoylethanolamide reduces formalin-induced neuropathic-like behaviour through spinal glial/microglial phenotypical changes in mice," CNS \& Neurological Disorders-Drug Targets, vol. 12, no. 1, pp. 45-54, 2013.

[38] I. Bettoni, F. Comelli, A. Colombo, P. Bonfanti, and B. Costa, "Non-neuronal cell modulation relieves neuropathic pain: efficacy of the endogenous lipid palmitoylethanolamide," CNS and Neurological Disorders: Drug Targets, vol. 12, no. 1, pp. 34-44, 2013.

[39] I. Paterniti, D. Impellizzeri, R. Crupi et al., "Molecular evidence for the involvement of PPAR-delta and PPAR-gamma in anti-inflammatory and neuroprotective activities of palmitoylethanolamide after spinal cord trauma," Journal of Neuroinflammation, vol. 10, article 20, 2013.

[40] R. Citraro, E. Russo, F. Scicchitano et al., "Antiepileptic action of $N$-palmitoylethanolamine through CB1 and PPAR- $\alpha$ receptor activation in a genetic model of absence epilepsy," Neuropharmacology, vol. 69, pp. 115-126, 2013.

[41] E. Esposito, I. Paterniti, M. Campolo, M. Cordaro, and S. Cuzzocrea, "The association of palmitoylethanolamide with luteolin reduces neurotoxicity and apoptosis in amyloid-beta stressed hippocampal organotypic slice cultures," in The Role of Pharmacological Research for the Growth and Health, Pharmacology CotISo, Ed., Council of the Italian Society of Pharmacology, Turin, Italy, 2013.

[42] R. Di Paola, D. Impellizzeri, P. Mondello et al., "Palmitoylethanolamide reduces early renal dysfunction and injury caused by experimental ischemia and reperfusion in mice," Shock, vol. 38, no. 4, pp. 356-366, 2012.

[43] E. Esposito, D. Impellizzeri, E. Mazzon, I. Paterniti, and S. Cuzzocrea, "Neuroprotective activities of palmitoylethanolamide in an animal model of Parkinson's disease," PLOS ONE, vol. 7, no. 8, Article ID e41880, 2012.

[44] A. Ahmad, R. Crupi, D. Impellizzeri et al., "Administration of palmitoylethanolamide (PEA) protects the neurovascular unit and reduces secondary injury after traumatic brain injury in mice," Brain, Behavior, and Immunity, vol. 26, no. 8, pp. 13101321, 2012.

[45] E. Esposito, I. Paterniti, E. Mazzon et al., "Effects of palmitoylethanolamide on release of mast cell peptidases and neurotrophic factors after spinal cord injury," Brain, Behavior, and Immunity, vol. 25, no. 6, pp. 1099-1112, 2011.

[46] T. Genovese, E. Esposito, E. Mazzon et al., "Effects of palmitoylethanolamide on signaling pathways implicated in the development of spinal cord injury," The Journal of Pharmacology and Experimental Therapeutics, vol. 326, no. 1, pp. 12-23, 2008.
[47] A. Kumar, Z. Qiao, P. Kumar, and Z.-H. Song, "Effects of palmitoylethanolamide on aqueous humor outflow," Investigative Ophthalmology \& Visual Science, vol. 53, no. 8, pp. 44164425, 2012.

[48] G. Duff, A. Argaw, B. Cecyre et al., "Cannabinoid receptor $\mathrm{CB}_{2}$ modulates axon guidance," PLoS ONE, vol. 8, no. 8, Article ID e70849, 2013.

[49] J. E. Slusar, E. A. Cairns, A.-M. Szczesniak, H. B. Bradshaw, A. Di Polo, and M. E. M. Kelly, "The fatty acid amide hydrolase inhibitor, URB597, promotes retinal ganglion cell neuroprotection in a rat model of optic nerve axotomy," Neuropharmacology, vol. 72, pp. 116-125, 2013.

[50] G. Krishnan and N. Chatterjee, "Endocannabinoids alleviate proinflammatory conditions by modulating innate immune response in muller glia during inflammation," Glia, vol. 60, no. 11, pp. 1629-1645, 2012.

[51] N. Sepe, L. De Petrocellis, F. Montanaro, G. Cimino, and V. Di Marzo, "Bioactive long chain $N$-acylethanolamines in five species of edible bivalve molluscs: possible implications for mollusc physiology and sea food industry," Biochimica et Biophysica Acta, vol. 1389, no. 2, pp. 101-111, 1998.

[52] V. di Marzo and S. D. Skaper, "Palmitoylethanolamide: biochemistry, pharmacology and therapeutic use of a pleiotropic anti-inflammatory lipid mediator," CNS \& Neurological Disorders-Drug Targets, vol. 12, no. 1, pp. 4-7, 2013.

[53] J. M. Keppel Hesselink, "New targets in pain, non-neuronal cells, and the role of palmitoylethanolamide," The Open Pain Journal, vol. 5, no. 1, pp. 12-23, 2012.

[54] J. M. Keppel Hesselink, "Chronic idiopathic axonal neuropathy and pain, treated with the endogenous lipid mediator palmitoylethanolamide: a case collection," International Medical Case Reports Journal, vol. 6, no. 1, pp. 49-53, 2013.

[55] A. Truini, A. Biasiotta, G. Di Stefano et al., "Palmitoylethanolamide restores myelinated-fibre function in patients with chemotherapy-induced painful neuropathy," CNS \& Neurological Disorders-Drug Targets, vol. 10, no. 8, pp. 916-920, 2011.

[56] F. A. Kuehl, T. A. Jacob, O. H. Ganley, R. E. Ormond, and M. A. P. Meisinger, "The identification of N-(2-hydroxyethyl)palmitamide as a naturally occurring anti-inflammatory agent," Journal of the American Chemical Society, vol. 79, no. 20, pp. 5577-5578, 1957.

[57] F. Perlik, J. Elis, H. Rakovfi et al., "Controlled clinical trial with PEA in childreninstitutions," Cs Fysiol, vol. 18, pp. 345-346, 1969.

[58] K. Mašek, F. Perlík, J. Klíma, and R. Kahlich, "Prophylactic efficacy of N-2-hydroxyethyl palmitamide (Impulsin) in acute respiratory tract infections," European Journal of Clinical Pharmacology, vol. 7, no. 6, pp. 415-419, 1974.

[59] J. M. Keppel Hesselink, T. de Boer, and R. F. Witkamp, "Palmitoylethanolamide: a natural body-own anti-inflammatory agent, effective and safe against influenza and common cold," International Journal of Inflammation, vol. 2013, Article ID 151028, 8 pages, 2013.

[60] D. E. Epps, P. C. Schmid, V. Natarajan, and H. H. O. Schmid, " $N$-acylethanolamine accumulation in infarcted myocardium," Biochemical and Biophysical Research Communications, vol. 90, no. 2, pp. 628-633, 1979.

[61] V. Natarajan, P. C. Schmid, P. V. Reddy, M. L. Zuzarte-Augustin, and H. H. Schmid, "Biosynthesis of N-acylethanolamine phospholipids by dog brain preparations," Journal of Neurochemistry, vol. 41, no. 5, pp. 1303-1312, 1983. 
[62] V. Natarajan, P. C. Schmid, P. V. Reddy, M. L. Zuzarte-Augustin, and H. H. O. Schmid, "Occurrence of $N$-acylethanolamine phospholipids in fish brain and spinal cord," Biochimica et Biophysica Acta, vol. 835, no. 3, pp. 426-433, 1985.

[63] A. Leon, A. Buriani, R. Dal Toso et al., "Mast cells synthesize, store, and release nerve growth factor," Proceedings of the National Academy of Sciences of the United States of America, vol. 91, no. 9, pp. 3739-3743, 1994.

[64] J. M. Keppel Hesselink, "Evolution in pharmacologic thinking around the natural analgesic palmitoylethanolamide: from nonspecific resistance to PPAR- $\alpha$ agonist and effective nutraceutical," Journal of Pain Research, vol. 6, pp. 625-634, 2013.

[65] L. Aloe, A. Leon, and R. Levi-Montalcini, "A proposed autacoid mechanism controlling mastocyte behaviour," Agents and Actions, vol. 39, pp. C145-C147, 1993.

[66] F. Abramo, L. Campora, F. Albanese et al., "Increased levels of palmitoylethanolamide and other bioactive lipid mediators and enhanced local mast cell proliferation in canine atopic dermatitis," BMC Veterinary Research, vol. 10, article 21, 2014.

[67] J. LoVerme, G. La Rana, R. Russo, A. Calignano, and D. Piomelli, "The search for the palmitoylethanolamide receptor," Life Sciences, vol. 77, no. 14, pp. 1685-1698, 2005.

[68] J. Lo Verme, J. Fu, G. Astarita et al., "The nuclear receptor peroxisome proliferator-activated receptor- $\alpha$ mediates the antiinflammatory actions of palmitoylethanolamide," Molecular Pharmacology, vol. 67, no. 1, pp. 15-19, 2005.

[69] G. G. Muccioli and N. Stella, "Microglia produce and hydrolyze palmitoylethanolamide," Neuropharmacology, vol. 54, no. 1, pp. 16-22, 2008.

[70] D. Baker, G. Pryce, J. L. Croxford et al., "Endocannabinoids control spasticity in a multiple sclerosis model," The FASEB Journal, vol. 15, no. 2, pp. 300-302, 2001.

[71] R. di Paola, D. Impellizzeri, A. Torre et al., "Effects of palmitoylethanolamide on intestinal injury and inflammation caused by ischemia-reperfusion in mice," Journal of Leukocyte Biology, vol. 91, no. 6, pp. 911-920, 2012.

[72] S. Assaw, A. Bennett, V. Chapman, J. Burston, and G. Hathway, "The role of N-palmitoylethanolamide in inhibition of the carrageenan induced inflammatory pain response," in Proceedings of the 8th 'Pain In Europe' Congress (EFIC '13), Florence, Italy, October 2013.

[73] K. Kono, Y. Kamijo, K. Hora et al., "PPAR $\alpha$ attenuates the proinflammatory response in activated mesangial cells," American Journal of Physiology-Renal Physiology, vol. 296, no. 2, pp. F328-F336, 2009.

[74] Y. Matsushita, D. Ogawa, J. Wada et al., "Activation of peroxisome proliferator-activated receptor $\delta$ inhibits streptozotocininduced diabetic nephropathy through anti-inflammatory mechanisms in mice," Diabetes, vol. 60, no. 3, pp. 960-968, 2011.

[75] S. Cerrato, P. Brazis, M. F. della Valle, A. Miolo, and A. Puigdemont, "Effects of palmitoylethanolamide on immunologically induced histamine, $\mathrm{PGD}_{2}$ and TNF $\alpha$ release from canine skin mast cells," Veterinary Immunology and Immunopathology, vol. 133, no. 1, pp. 9-15, 2010.

[76] G. Mattace Raso, R. Russo, A. Calignano, and R. Meli, "Palmitoylethanolamide in CNS health and disease," Pharmacological Research, vol. 86, pp. 32-41, 2014.

[77] G. D’Agostino, R. Russo, C. Avagliano, C. Cristiano, R. Meli, and A. Calignano, "Palmitoylethanolamide protects against the amyloid-B25-35-induced learning and memory impairment in mice, an experimental model of alzheimer disease," Neuropsychopharmacology, vol. 37, no. 7, pp. 1784-1792, 2012.
[78] M. M. Nentwich and M. W. Ulbig, "Diabetic retinopathyocular complications of diabetes mellitus," World Journal of Diabetes, vol. 6, no. 3, pp. 489-499, 2015.

[79] E. Lontchi-Yimagou, E. Sobngwi, T. E. Matsha, and A. P. Kengne, "Diabetes mellitus and inflammation," Current Diabetes Reports, vol. 13, no. 3, pp. 435-444, 2013.

[80] C. Costagliola, V. Romano, M. De Tollis et al., “TNF-alpha levels in tears: a novel biomarker to assess the degree of diabetic retinopathy," Mediators of Inflammation, vol. 2013, Article ID 629529, 6 pages, 2013.

[81] Y. Yu, H. Chen, and S. B. Su, "Neuroinflammatory responses in diabetic retinopathy," Journal of Neuroinflammation, vol. 12, no. 1, article 141, 2015.

[82] C. M. McVicar, M. Ward, L. M. Colhoun et al., "Role of the receptor for advanced glycation endproducts (RAGE) in retinal vasodegenerative pathology during diabetes in mice," Diabetologia, vol. 58, no. 5, pp. 1129-1137, 2015.

[83] K. K. Zhou, S. Benyajati, Y. Le, R. Cheng, W. Zhang, and J.-X. $\mathrm{Ma}$, "Interruption of Wnt signaling in müller cells ameliorates ischemia-induced retinal neovascularization," PLOS ONE, vol. 9, no. 10, Article ID e108454, 2014.

[84] X. Chen, H. Zhou, Y. Gong, S. Wei, and M. Zhang, "Early spatiotemporal characterization of microglial activation in the retinas of rats with streptozotocin-induced diabetes," Graefe's Archive for Clinical and Experimental Ophthalmology, vol. 253, no. 4, pp. 519-525, 2015.

[85] Y. Liu, M. Costa, and C. Gerhardinger, "IL- $1 \beta$ is upregulated in the diabetic retina and retinal vessels: cell-specific effect of high glucose and IL-1 $\beta$ autostimulation," PLoS ONE, vol. 7, no. 5, Article ID e36949, 2012.

[86] A. Énzsöly, A. Szabó, K. Szabó, Á. Szél, J. Németh, and Á. Lukáts, "Novel features of neurodegeneration in the inner retina of early diabetic rats," Histology and Histopathology, vol. 30, no. 8, pp. 971-985, 2015.

[87] U. Rajamani and I. Jialal, "Hyperglycemia induces Toll-like receptor- 2 and -4 expression and activity in human microvascular retinal endothelial cells: implications for diabetic retinopathy," Journal of Diabetes Research, vol. 2014, Article ID 790902, 15 pages, 2014.

[88] H. Wang, H. Shi, J. Zhang et al., "Toll-like receptor 4 in bone marrow-derived cells contributes to the progression of diabetic retinopathy," Mediators of Inflammation, vol. 2014, Article ID 858763, 7 pages, 2014.

[89] K. Singh, S. Kant, V. K. Singh, N. K. Agrawal, S. K. Gupta, and K. Singh, "Toll-like receptor 4 polymorphisms and their haplotypes modulate the risk of developing diabetic retinopathy in type 2 diabetes patients," Molecular Vision, vol. 20, pp. 704713,2014 


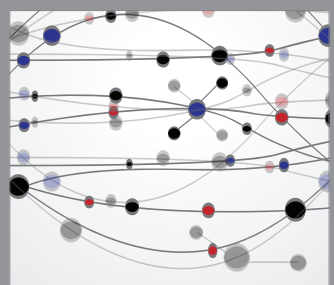

The Scientific World Journal
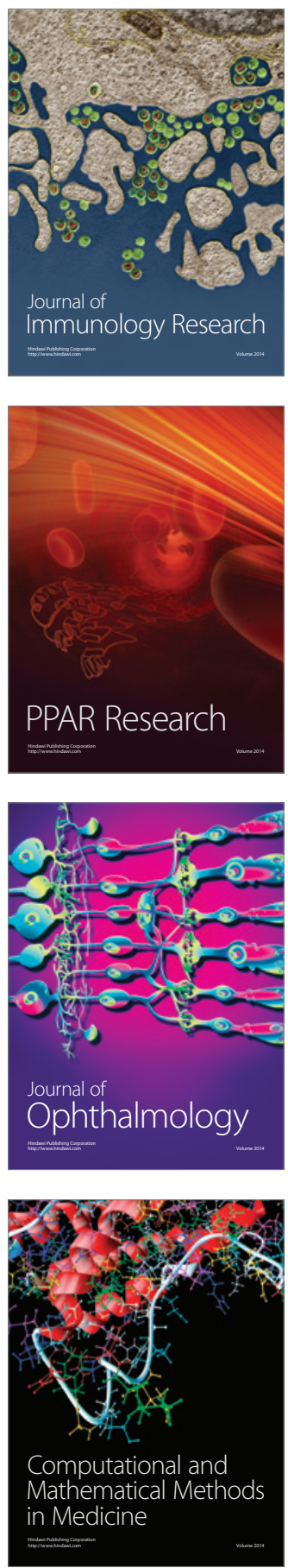

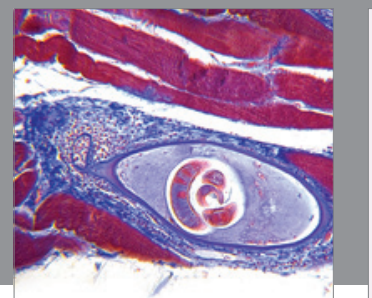

Gastroenterology

Research and Practice
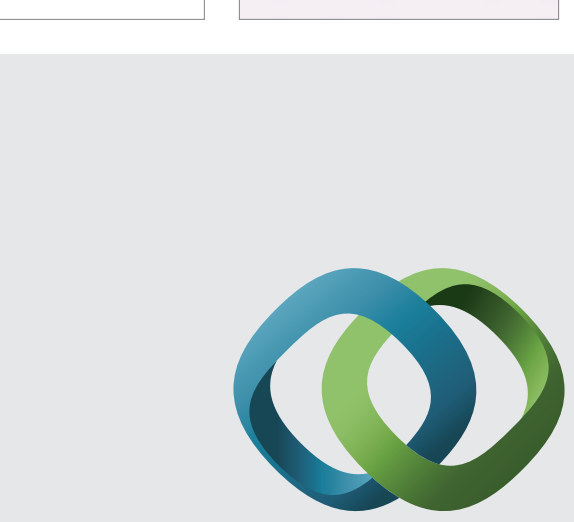

\section{Hindawi}

Submit your manuscripts at

http://www.hindawi.com
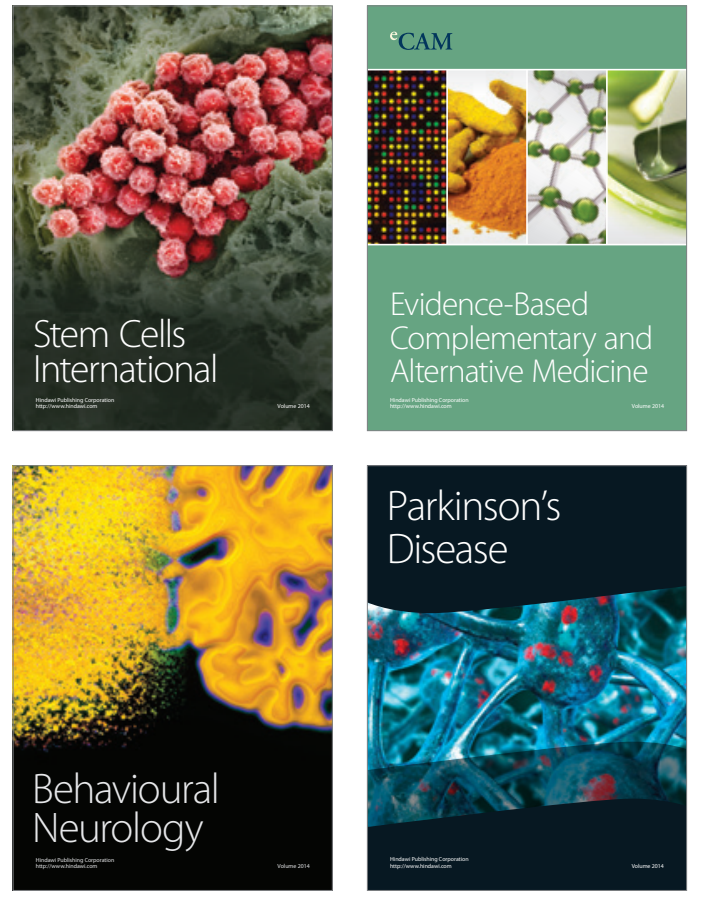
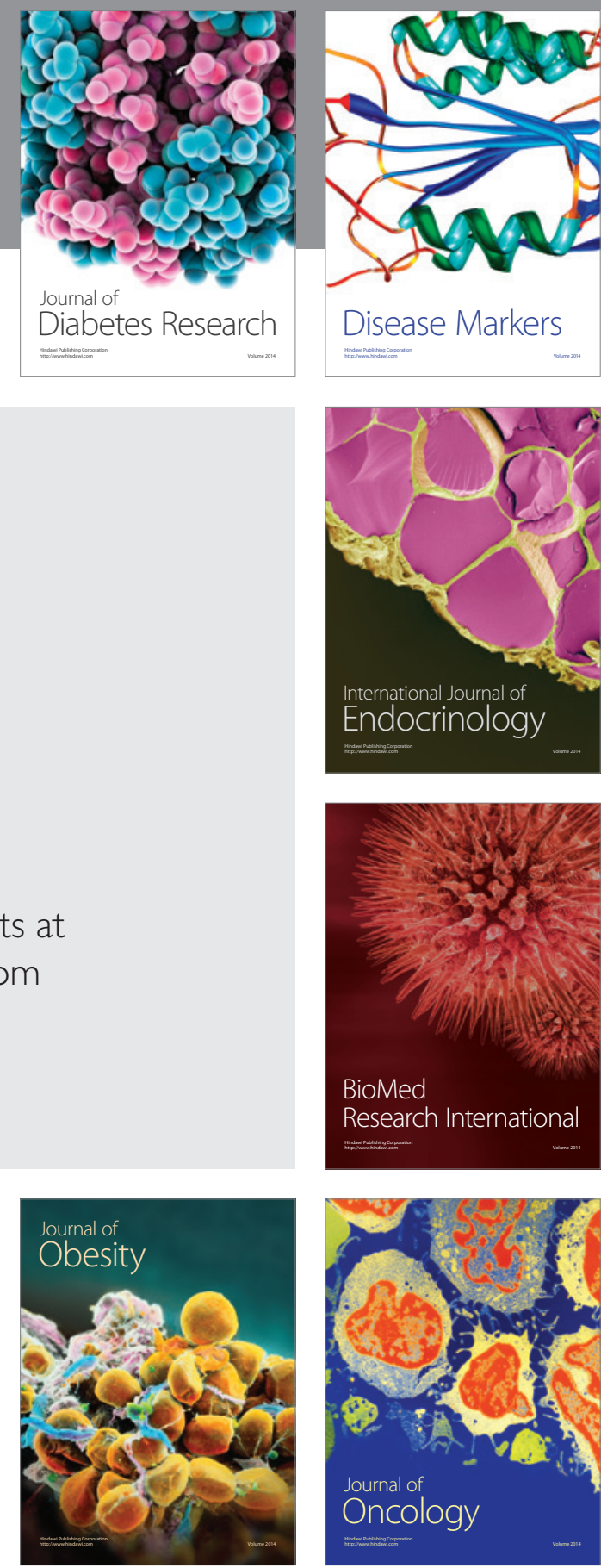

Disease Markers
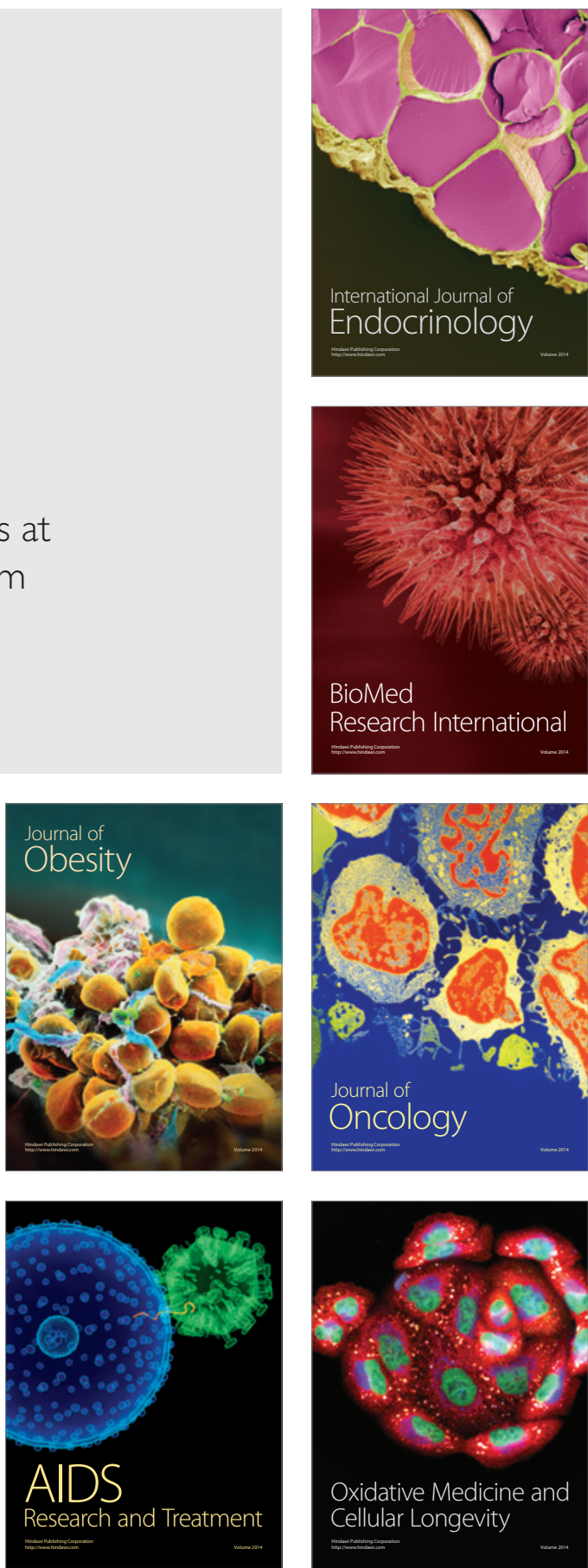